This is the accepted version of the following article:

Graham, N., Nye, C., Mandy, A., Clarke, C., Morriss-Roberts, C. (2017e) The meaning of play for children and young people with physical disabilities: A systematic thematic synthesis. Child: Health, Care and Development, September:1-10.

DOI: $10.1111 /$ cch.12509

This article may be used for non-commercial purposes in accordance with Wiley Terms and Conditions for Self-Archiving.

\title{
The meaning of play for children and young people with physical disabilities: A systematic thematic synthesis
}

\section{Play for children with physical disabilities}

Naomi Graham, MSc, BSc(Hons), PhD student.

University of Brighton, 49 Darley Road, Eastbourne, BN20 7UR, UK

Dr Clemency Nye, BA, MBBS, Clinical Fellow.

North Bristol NHS Trust, Southmead Hospital Bristol, Southmead Road, Westbury-on-Trym, Bristol, BS10 5NB

Dr Anne Mandy, PhD, MSc, BSc(Hons), Associate Professor.

University of Brighton, 49 Darley Road, Eastbourne, BN20 7UR UK

Dr Channine Clarke, PhD, MSc, BSc(Hons), Academic lead, Occupational Therapy.

University of Brighton, 49 Darley Road, Eastbourne, BN20 7UR, UK

Dr Christopher Morriss-Roberts, PhD, MA, BSc(Hons), Course Leader MSc Podiatry. University of Brighton, 49 Darley Road, Eastbourne, BN20 7UR, UK

Keywords:

Play, Disability, Physical Disabilities, Children's Views, Qualitative, Systematic Review.

Conflicts of interest: none to declare 
The meaning of play for children and young people with physical disabilities: A systematic thematic synthesis

\begin{abstract}
Background: Children and young people with physical disabilities are often reported to play less than their typically developing peers. Few studies explore the meaning of play from the child's perspective; this study carried out a thematic synthesis of the findings of qualitative studies about the meaning of play following the PRISMA guidelines.
\end{abstract}

Methods: A search of CINAHL, AHMED, PsycINFO, MEDLINE, EMBASE and ERIC was undertaken between September 2015 and March 2016. Qualitative studies exploring the meaning of play from the perspective of 0-18year olds with physical disabilities impacting function were included. Quality appraisal and thematic synthesis were undertaken in order to develop analytical themes.

Results: Thirteen studies met the inclusion criteria in part addressing the meaning of play for children and young people with physical disabilities. Synthesis of the findings identified five analytical themes: play can feel both positive and negative; play can draw attention towards or away from my disability; play is a social interaction; I participate differently to my peers, and needing help feels normal.

Conclusions: The themes highlight the potential for play experiences of individuals with physical disabilities being overlooked by parents and professionals; further research is needed to explore play experience from these individual's perspective. 


\section{Introduction}

Play is considered a significant everyday activity for children, valuable to their health and wellbeing, across a wide range of fields such as psychology, healthcare and early years education (Chandler, 1997; Chiarello et al., 2006; Lester \& Russell, 2008; Robinson, 2011; Whitebread et al., 2012). Play is a right for every child (UNICEF 1989) and is most understood from the perspective of the player (McInnes et al., 2009). This review used quality appraisal (Garside, 2013) and thematic synthesis (Thomas \& Harden, 2008) to develop analytical themes surrounding the meaning of play for children with physical disabilities. The theoretical framework impacting upon this review is pinned upon the value of, and right to, play and a biopsychosocial model of disability, as used within the International Classification of Functioning, which views an individual's participation in activity as an interaction between health condition, body function, personal factors, and environment (World Health Organisation, 2007).

Play is often referred to as a multidimensional and complex concept which is difficult to define, and varies according to every individual's perspective (Neumann 1971; Reilly, 1974). Neumann (1971) discusses ‘the problem of play' describing how child development, education, and the function of play have all driven varying play definitions. Play is an activity often defined by its freedom, choice and control (Sheridan et al., 2011). Freedom within play, also described as internal reality, is the concept that the player's reality is suspended and play is directed by their own volition (Schiller, 1954), this can lead to play being experienced as 'flow' (Csikszentmihalyi \& Bennett, 1971). Choice within play is closely linked to the child's motivation (Bundy, 2012); all children are considered to have a natural drive towards spontaneous play (Sheridan, 2011). Internal control suggests the process and objective of the play is controlled by the player (Bundy, 2012). Parten (1934) suggested internal control can also be experienced through cooperative control, when an individual chooses to share their play with others. Bundy (2012) argues a 'frame' of play cues such as an exaggerated use of props, voices or bodies, can lead to an activity being viewed as play. This article follows a definition of play as an activity of freedom, choice, and control framed by cues that an individual is playing (Sheridan et al. 2011, Bundy 2012).

According to Article 31 of the United Nations Convention of the Rights of the Child, every child has the right to play (UNICEF, 1989). Despite this, the research literature suggests that children with disabilities demonstrate less playfulness than their typically developing peers 
(Imms et al., 2017; King et al., 2009; Kolehmainen et al., 2011; Whittingham et al., 2010). In response to this, health and educational professionals have sought to increase opportunities for playfulness in children with disabilities (Bundy, 2012; Whitebread et al., 2013). This, has led to the proposal that academics, health and educational professionals, and parents should recognise the intrinsic value of free play for children with disabilities, rather than purely viewing play as a tool for therapy or education (Goodley \& Runswick-Cole, 2010).

As play experience varies according to the perspective of the player, it is important to consider the child's perspective of play (Chandler, 1997; McInnes et al., 2009). Several studies, predominantly in the education field, have researched play from the perspective of typically developing children. These mainly suggest children view play as separate to work and without adult direction, as an activity which is fun and chosen by themselves (Berkhout et al., 2013; Gmitrova et al., 2009; Howard, 2002; Howard et al., 2006; King, 1979; King \& Howard, 2014; Rogers \& Evans, 2006; Wing, 1995). As children with disabilities are thought to play less than their typically developing peers (Imms et al., 2017), it is important to also consider the meaning of play from their perspective. Polatakjo et al. (2007) suggests that individuals can be fully engaged and participating within activity despite limited performance; this may also be the case for play.

Participation within play is an important part of a child's leisure activities and is defined as such by the international classification of functioning, disability and health: children and youth version (ICF-CY) (World Health Organisation, 2007). Although considered a part of leisure activities, play as a concept is defined separately from leisure. Play is typically an internally motivated behaviour marked by a lack of structure, which can occur during work or leisure; while leisure is time outside of work and self-care activities, which can involve participation in an organised activity but might include reflection, relaxation or spiritual experiences (Mclean \& Hurd, 2011). This review focuses specifically on play and therefore contrasts to the work of Powrie et al. (2015), whose review focused broadly on the concept of leisure for children and young people with physical disabilities. This review focusses on the concept of play but used 'leisure' as well as 'play' within the search strategy in order to ensure inclusion of all potentially relevant articles.

This study aims to synthesise the findings presented in qualitative studies which help to explore the meaning of play for children and young people with physical disabilities. As qualitative research is often best placed to capture individual feelings or experience of a 
concept (Garside, 2013) only qualitative data was sought within this review in order that thematic synthesis could occur. The PRISMA guidelines for reporting systematic reviews (Moher et al., 2009) were followed in the process of writing this article in order to ensure a rigorous and trustworthy review.

\section{Methods}

\section{Search Strategy}

The following databases were searched between September 2015 and March 2016: CINHAL, psychINFO, AMED, MEDLINE, EMBASE and ERIC. The following strategies were used.

- CINAHL, MeSH terms:

- Population- child (explode) OR child, preschool OR adolescence (explode) OR "youth" OR young people AND disabled (explode) OR "physical disab*”

○ Subject of interest- AND "play and playthings" (explode) OR "Leisure activities" (explode) OR recreation (explode)

○ Outcome- AND "self report" (explode) OR perception (explode) OR "Qualitative studies" (explode)

- $\quad$ psychINFO, AMED, MEDLINE, EMBASE and ERIC:

○ Population- child* OR child, preschool OR adolescen* OR youth OR "young people" AND disabled OR "physical disab*"

○ Subject of interest- AND play* OR "leisure activit*" OR recreation

○ Outcome- AND qualitative OR perception OR "self report"

University librarians were asked to provide advice with regards to the search strategy to ensure a thorough search. The search strategy did not use any limits on the date of publication so all studies relevant to the review in this under researched area of study could be included. The screening and analysis process was carried out by the first two authors (NG, CN) separately and then discussed to refine and agree on both descriptive and analytical themes.

Articles were included if they involved:

- $\quad$-18 year olds with physical disabilities impacting their functional ability;

- Some discussion of play experience from the perspective of children and young people (not necessarily the primary focus of the study, for example could be a mention of 'play' within a quote; one theme within a qualitative study which referred to play; or the view of one child with an identified physical disability); 
- Qualitative methodology (qualitative elements of mixed method studies considered);

- Findings available in English (as no translator was available).

Studies focusing on an intervention were included if the findings discussed play experience which was referred to as 'play' within the article.

Studies were initially screened according to title and abstracts by the first author (NG). This resulted in several articles being excluded through not meeting inclusion criteria (e.g. focusing on a non-physical disability such as autism, quantitative articles, teacher or professional perspectives). This provided a method of quickly identifying articles which were not relevant to the review, allowing full text to be read only when necessary (Kable et al., 2012). This was carried out by NG for pragmatic reasons of use of time; any articles where there was any doubt were included and screened in full. Of the remaining articles, reference lists were screened to include any further relevant studies. Then articles were read in full by both NG and CN independently; agreement was unanimous as to which of the 44 screened articles were included or excluded according to the criteria discussed above (reasons provided in Figure 1).

\section{Quality appraisal}

Following identification of articles relevant to the review, quality appraisal using Garside's (2013) criteria was undertaken by the first two authors (NG, CN). This suggests reviewing each article according to clarity of questions, suitability to qualitative study, clear context, sampling, data collection and analysis (Garside, 2013). Issues of trustworthiness such as appropriateness of design, ethical considerations and reporting of the participant's voice were also considered. Theoretical considerations - such as connection to a wider body of knowledge or theoretical framework - and practical considerations - such as, the application of the study to the present review - were also important (Garside, 2013). If an article had poor quality of questions, unclear context, sampling, data collection and analysis it was excluded from the present review.

\section{Thematic synthesis}

Several methods such as meta-synthesis, meta-interpretation and constant comparison, are presented within the literature for synthesising qualitative studies; the most currently used approach is meta-ethnography (Dixon-Woods et al., 2007). The Centre for Reviews and Dissemination (2008), also highlights thematic synthesis as one possible method allowing for 
identification of important or recurring themes. Thematic synthesis draws upon the theory of thematic analysis, which is applied to the analysis of qualitative data (Thomas \& Harden, 2008). It involves line-by-line coding of included sections of articles, then grouping together codes to create descriptive themes (Nicholson et al., 2016). The themes identified are then used to explore the research question and create analytical themes relevant to the review (Thomas \& Harden, 2008). The first two authors (NG, CN) were aware of the difficulties of aggregating qualitative findings from various contexts, however, concur with Bearman $\&$ Dawson (2013) that a synthesis of research can provide a helpful contribution to practice. The process of independently creating descriptive themes and discussing and agreeing these before doing the same for analytical themes enabled a consensus grounded within the theoretical framework outlined in the introduction; this transparency of process helps to improve the rigour and credibility of this review (Bearman \& Dawson 2013). This occurred through cutting out each authors list of themes and subthemes and in discussion grouping and re-grouping them until themes were agreed.

One advantage of thematic synthesis is that it can 'go beyond' a description of studies findings (Thomas \& Harden, 2008). This is particularly applicable within this field as very few studies have specific aims to capture the meaning of play for children and young people with physical disabilities. Developing analytical themes allows a broader understanding which would otherwise not be possible.

\section{Results}

Systematic searching of the literature and reference lists of identified articles led to the identification of 13 articles relevant to this review (Figure 1). The articles identified are summarised in table 1. Quality appraisal of the articles suggested all 13 articles were of sufficient quality to be included within the review (see Table 1). Children and young people (age 0-18 years) within this review are referred to as children to describe the participant group more easily. Although seminal work recognises the differences in participation in play across ages and between children and youth (Sheridan et al., 2011), many studies reporting children's perspectives of play span 0-18yr olds and therefore are all included. When used pseudonyms from original studies are given. 
*insert figure 1 here* Figure 1 Flow diagram demonstrating the search process and identification of articles for review.

*insert table 1 here* Table 1 Summary of articles included within thematic synthesis

\section{Developing descriptive themes}

Each relevant section within the findings and discussion of identified papers was read, coded and grouped into descriptive themes. Three descriptive themes with twelve sub-themes were discussed and agreed upon which captured and described meaning of play from the children's view point. These themes are: play feels positive; I can be excluded from play; I sometimes play differently to my peers. The use of first person was deemed appropriate in order to reflect the perspective of children and young people captured within the articles. The key themes and sub-themes are summarised and briefly discussed below, highlighted in bold font.

\section{Play feels positive}

Within some of the studies children demonstrated how they can play on their own and this was a positive experience (Burke, 2012; Miller \& Reid, 2003). Play was often described by children as fun, happy and good (Burke, 2012; Miller \& Reid, 2003; Pollock et al., 1997). Children often referred to the importance of playing with their friends (Burke, 2012; Mundhenke et al., 2010; Schiariti et al., 2014; Skär, 2002; Spencer-Cavaliere \& Watkinson, 2010; Young et al., 2007). They enjoy competition within play and the opportunity to do this alongside their peers (Miller \& Reid, 2003; Schiariti et al., 2014; Spencer-Cavaliere \& Watkinson, 2010). Children also referred to their equipment in a positive light suggesting that equipment helps them play (Gcaza \& Lorenzo, 2008; Miller \& Reid, 2003; Skär, 2002; Sonday \& Gretschel, 2016).

\section{I can be excluded from play}

Many of the articles also had a focus towards times that the children had felt excluded from play (Skär, 2002; Spencer-Cavaliere \& Watkinson, 2010). Children felt there was a lack of equipment or adaptation to support their play (Egilson \& Traustadottir 2009; Gcaza \& Lorenzo, 2008; Ripat \& Becker, 2012; Skär, 2002). Children often reported a feeling that no one wanted to play with them (Egilson \& Traustadottir, 2009; Gcaza \& Lorenzo, 2008; Miller \& Reid, 2003; Mundhenke et al., 2010; Spencer-Cavaliere \& Watkinson, 2010; Tamm \& Skär, 2000). The nature of each child's physical disability often also led to them being 
excluded from play because they needed breaks for care routines (Pollock et al., 1997; Tamm \& Skär, 2000).

\section{I sometimes play differently to my peers}

Some studies also discussed play that was different to typically developing children: children reported participating in play by watching a game (Buchanan, 2009; Gcaza \& Lorenzo, 2008; Pollock et al., 1997; Schiariti et al., 2014; Tamm \& Skär, 2000). Children often reported participating in play with adults (Buchanan, 2009; Gcaza \& Lorenzo, 2008; Skär, 2002; Spencer-Cavaliere \& Watkinson, 2010). When they had the opportunity to play with others children often chose to follow the lead of others, this enabled them to be able to participate in the play activity (Burke, 2012; Egilson \& Traustadottir, 2009; Mundhenke et al., 2010; Pollock et al., 1997; Miller \& Reid, 2003; Tamm \& Skär, 2000; Spencer-Cavaliere \& Watkinson, 2010). Children also expressed that they have to ask to play (Gcaza \& Lorenzo, 2008; Mundhenke et al., 2010; Pollock et al. 1997; Spencer-Cavaliere \& Watkinson, 2010; Tamm \& Skär, 2000).

\section{Developing analytical themes}

The descriptive themes were then synthesised independently, discussed, and agreed upon in order to 'go beyond' the initial meaning of the data and apply it to the context of this review (Thomas \& Harden, 2008). The following analytical themes exploring the meaning of play for children with physical disabilities were a result of this synthesis:

I. Play can feel both positive and negative

II. Play can draw attention both towards or away from my disability

III. Play is a social interaction

IV. I participate differently to my peers

V. Needing a helper feels normal

The links between the descriptive themes and the resulting analytical themes is show in figure two.

*Insert figure 2 here* Figure 2 Links between descriptive themes and analytical themes

\section{Play can feel both positive and negative}


Children within the studies described many powerful emotions linked to play experiences. Several studies commented on the fact that playing for children with physical disabilities often meant compromise in choice.

'I mostly play alone. I have no choice. I'm almost never allowed to be in the games, because it doesn't suit the others' Child (Tamm \& Skär, 2000, p.178).

'.It usually wasn't me who chose because if I ever did get someone to play with, I usually said 'Okay, you're playing with me, that's good enough, like, you choose.' Young person, age 17 (Pollock et al., 1997, p.29).

'At first they [the other children] thought that I wasn't any good at it. They said, 'No, you can't be goalie." Then another guy, who was my friend, said, 'Yes, but couldn't he try?!" Child, (Mundhenke et al., 2010, p.135).

Despite this, when children were included lots of positive emotions were linked to play.

'And they would let me join in games and that made me feel really, really good and I was all happy and everything. Like sometimes they wouldn't let me join, but sometimes I wasn't okay with it and sometimes I was.' Brandon, age 12 (SpencerCavaliere \& Watkinson, 2010, p.282).

'Well, basically I like most of the games because I like all of them, because they're easy to do and they're fun. That's like, easy for me to do.' Vincent age range 8-13 (Miller \& Reid, 2003, p.628).

\section{Play can draw attention towards or away from my disability}

Playing for children with physical disabilities appeared to have meaning attached to being included with peers and being like everyone else. This appeared to lead to attention being drawn away from the child's disability. The following quote shows how participation in virtual reality means the child stops thinking about their physical disability.

'You can visualise... all these things like you stopping the winning goal, you scoring the winning point. This is kinda like making a dream come alive.' Samuel (Miller \& Reid, 2003, p.629). 
Being with a group of peers known to a child helped to draw attention away from their disability.

'I hang out more with friends who act like I'm not different. Like, they treat me like

I'm the exact same. They treat me... you know, they just don't be like, "oh she has a disability we have to walk slow." They just do it'. Girl (Schiariti et al., 2014, p.858).

On the other hand, children often spoke about how their disability was made more apparent during play activities. The following quote demonstrates how this happens when groups of children play and one child feels excluded.

'I watch my friends playing nopentana [form of indigenous skipping using old pantehose] sitting on the floor rug that my mother put outside for me, they talked and laughed together as if I was not there. I sometimes cried when my mother took me inside.' (Gcaza \& Lorenzo, 2008, p.19).

Despite this, for some children their disability being seen as apparent was positive for their play.

'They were all cheering for me, "yeah Brandon!" and in kick ball they know I have a disability and they're very cheerful they are like more cheerful for me, they cheer me on, with me, than with the other players.' Brandon, age 12 (Spencer-Cavaliere \& Watkinson, 2010, p.285).

\section{Play is a social interaction}

The importance of play as a social interaction for the children who participated in the study was clear through the way that they referred to play with their friends.

For some they felt that they missed out on play because they were not able to make friends.

'I think I was resigned to the fact that I couldn't, for whatever reason, that I couldn't have fun or that I couldn't play or that I didn't have friends. It's only now that I realize how much I've missed.' Girl (Pollock et al., 1997, p.29).

Being able to participate in play was a shared experience that took place alongside others. 
'Jessica said that being 'invited to come and play' would make her feel included because 'it makes you feel like they want you to play with them.' Jessica, age 12 (Spencer-Cavaliere \& Watkinson, 2010, p.282).

\section{I participate differently to my peers}

Children with physical disabilities reported how they participate in play in different ways, children emphasised the importance of being able to choose how they played. Children appeared to adapt their play in order that they could join in with their peers.

'William has strategically self-adapted his play to match his physical capabilities... Carl, like William, finds a way of engaging in peer play that allows him to avoid activities which are difficult and unpleasant but permit him to play with his friends.' Researcher's comments for William and Carl, age 10 (Burke, 2012, p.974).

Children reported participating in play through different means such as watching. This sometimes included more sedentary play like watching the iPad or more active play.

'...I don't really play at the park because I just want to go home and watch my iPad because I'm more of an inside guy. Um, but, um...that's basically it.' Boy age range 9-12 (Schiariti et al., 2014, p.858)

'It can be difficult to be in the game so I watch, but I'm still in the game somehow'. Child (Tamm \& Skär, 2000, p.178).

It was also clear that the children had to ask more than their peers as to if they could participate within a play activity.

'Well, I asked if I could play tag with them, and they said, "no you can't play with us". I went to the teacher, the teacher told the kids to let them play and then I asked after the teacher even said that, and they still said "no, you can't play". 'Jamie (Spencer-Cavaliere \& Watkinson, 2010, p.282).

\section{Needing a helper feels normal}

It appeared that many of the studies discussed the need for an adult or assistant to support a child with physical disabilities to participate in play. Facilitation was often needed due to 
difficulties with physical manipulation (Buchanan, 2009) and access to play (Tamm \& Skär, 2000). The need for help was sometimes seen as normal. It appeared that for some children a parent or assistant at school became a friend and playmate.

'She [the personal assistant] is my pal. Yes, she's actually with me always' Child (Tamm \& Skär, 2000, p.179).

'Once we (he and the assistant) built a railway.' Boy, age 6 (Skär, 2002, p.31)

One further important aspect of children needing a helper within play is that they often directed others to carry out the play where they were not physically able to do so.

Corey participated in and contributed to this form of play [pretend play] with signing and by directing his mother to incorporate signs or actions in the songs' Researcher (Buchanan, 2009, p.276).

\section{Discussion}

This thematic synthesis identified five analytical themes exploring the meaning of play for children and young people with physical disabilities. There are some similarities to Powrie et al.'s (2015) review of the meaning of leisure which was summarised to be 'fun', 'freedom', 'fulfilment' and 'friendship' (p.l). Despite this, the themes captured here would suggest that specific play experience is different to the broad experience of leisure. Although positive emotion and friendship are a part of play, the current findings also highlight different experiences of disability, understanding difference, and normalisation of help which also occur.

Although play is often described as an activity encompassing fun and enjoyment (Pollock et al., 1997), it is also recognised to be an activity which can incorporate serious and solemn emotions (Sheridan et al., 2011). This review highlights that children and young people with disabilities appear to report greater levels of frustration with play experiences due to exclusion from peers (Spencer-Cavaliere \& Watkinson, 2010; Tamm \& Skär, 2000). This level of exclusion and negative emotion contrasts to the play of typically developing children, which is usually described as fun and enjoyable (Wing, 1995). It is possible that this leads to children experiencing greater levels of fun and enjoyment when they participate in a play activity that is of value to them. This can be illustrated in the quotes described within the 
findings section above, such as 'that made me feel really, really good' (Spencer-Cavaliere \& Watkinson, 2010, p.282), where children's play experience may be felt with heightened emotion in comparison to their typically developing peers. Further research is needed to ascertain levels of frustration and enjoyment within the play of children with physical disabilities.

The findings suggest that sometimes when engaged within play children do not focus upon their disability; particularly when peers were accommodating. This is an area which requires further research into the perception of disability from the point of view of the player during a play activity. Csikszentmihalyi \& Bennett's (1971) theory of play as an activity in which one experiences flow from one action to another could help explain this. If a child with a disability experiences flow within play this may detract from them also thinking about or feeling their disability.

In contrast to this, some of the studies suggested that within play attention is drawn to a child's disability. This was experienced in both a positive and negative light but highlights the impact of physical disability on the meaning of play. Again, the impact of this is upon children with disabilities is not discussed within the literature and is important to explore.

Play as a social interaction is common to both typically developing children and children with disabilities in their understanding of play. Play alongside others is seen as reported as meaningful for typically developing children (Howard et al., 2006, Turnbull \& Jenvey, 2006). The current review echoes this, suggesting that children with physical disabilities place similar value on social interaction. This is highlighted in reports of play with peers increasing a sense of inclusion (Spencer-Cavaliere \& Watkinson, 2010). Literature suggests that parents of children with disabilities go through a process of normalisation in coming to terms with their child's disability (Hakstad et al., 2015). However, there currently appears to be little research addressing children's journey of making sense of a physical disability. It appears that being like everyone else in play can be a way in which children develop their identity and sense of self (Tamm \& Skär, 2000). This is an important area for future research where play for children with physical disabilities may differ from typically developing children if they are using this to explore and develop their sense of self.

The findings suggest that children participate in play differently to their peers. The idea that an individual can be engaged in an activity without fully participating physically (Polatajko et al., 2007) is reflected within studies exploring how children engage in play vicariously, 
through communication and through therapy (Graham et al., 2014). The idea of adaptation enabling participation is common within occupational therapy practice (Campbell et al., 2008). This appears to be a value reflected by children with physical disabilities on a subconscious level, in which they participate in play, a meaningful everyday occupation (Chiarello et al., 2006), in any way possible. The manner in which children participate differently needs further exploration.

Children were found to often feel the presence of a helper was a normal part of their play. This contrasts to the view of typically developing children who reported an activity to be more like play with no adult present (Howard, 2002, McInnes et al., 2009). The need for an adult to be a play partner for children with physical disabilities is frequently referred to (Buchanan, 2009; Graham et al., 2015; Hewitt-Taylor, 2009; Skär, 2002; Spencer-Cavaliere $\&$ Watkinson, 2010). Despite this, the impact of the presence of an adult on the experience of play is not adequately explored. As discussed within Tamm \& Skär's (2000) study, it is possible that the adult can become a barrier to other children playing with those who have physical disabilities because, as observations suggest, the adult may take over the game. They raise concerns this may increase children's dependability upon adults (Tamm \& Skär, 2000). As play provides opportunity for mastery and motivation (Shikako-Thomas et al., 2013), and is often defined by its freedom and choice (Neumann, 1971), it can be considered important that adults should follow the child's lead in play experience. This is reflected by parents interviewed by Buchanan (2009), who strongly emphasised following the lead of their child. If adults do not follow the child's lead it is possible that the meaning of the play experience of a child with physical disabilities will be very different to a typically developing child who has not needed the support of an adult.

\section{Limitations}

The synthesis of qualitative research studies is questioned due to the influence of the researcher, particularly when using research from a variety of contexts (Bearman \& Dawson, 2013; Thomas \& Harden, 2008). Despite this, it is argued that helpful contributions can be made if the researchers stance and synthesis process are reported with transparency (Bearman \& Dawson, 2013), this review has endeavoured to do this.

In order to gain a wide sample of studies relevant to the review, some involve observations made by the researchers alongside child report. This is helpful to some extent in gaining some understanding of the meaning of play for children with physical disabilities; however, it is 
limited in that it is not purely from the perspective of the child. It is recognised that the meaning of play varies according to the perspective of the player (Reilly, 1974; Sheridan et al., 2011). Further research should therefore take place from the perspective of children and young people with physical disabilities in order to develop an understanding from their perspective about the meaning of play.

\section{Conclusion}

The current synthesis has highlighted the potential for play experiences of individuals with disabilities being overlooked by parents, carers and professionals. The influence of peer and carer perceptions on children and young people's experiences is highlighted clearly within the analytical themes. This has implications for the recognition and value placed on play within early childhood settings, schools, communities, and healthcare settings, for children with disabilities. A greater recognition of a biopsychosocial perspective of disability is needed in order that the participation of children and young people with disabilities is not just seen through a medical lens (focusing on impairment), or a social lens (focusing on social context). It is imperative that further research is undertaken to capture the experience of play, an important primary occupation, from the perspective of children with physical disabilities. This will enable communities to learn to value and recognise each child's experience, allowing them to express their play rather than be viewed with a perspective of limitation.

\section{Key Messages}

- Play for children and young people with physical disabilities is different to their typically developing peers.

- Play can draw attention both towards and away from disability.

- Needing a helper within play can feel normal for children with physical disabilities.

- Further research is needed to explore the experience of play from the perspective of children and young people with physical disabilities. 


\section{References:}

Bearman, M., \& Dawson, P. (2013) Qualitative synthesis and systematic review in health professions education. Medical Education, 47, 252-260.

Berkhout, L., Bakkers, H., Hoekman, J., \& Goorhuis Brouwer, S.M. (2013) Observing free play in classrooms with an instrument based on video analysis. Early Child Development and Care, 183(1), 125-136.

Buchanan, M. (2009) The Home Play of Toddlers with Disabilities: Contexts and maternal perspectives. International Journal of Disability, Development and Education, 56(3), 263283.

Bundy, A. (2012) Children at Play: Can I Play, Too? In: Kids Can Be Kids: A Childhood Occupations Approach (ed. S.J. Lane, \& A.C. Bundy), pp. 28-43. F.A. Davis Company, Philadelphia, USA.

Burke J. (2012) 'Some kids climb up; some kids climb down': culturally constructed playworlds of children with impairments. Disability \& Society, 27(7), 965-981.

Campbell, P.H., Milbourne, S., \& Wilcox, J. (2008) Adaptation Interventions to Promote Participation in Natural Settings. Infants \& Young Children, 21(2), 94-106.

Centre for Reviews and Dissemination (CRD), (2008) Guidance for undertaking reviews in health care. University of York, York, UK.

Chandler, B. (1997) The Essence of Play: A Child's Occupation. The American Occupational Therapy Association Inc, Bethesda, USA.

Chiarello, L.A., Huntington, A., \& Bundy, A. A. (2006) Comparison of Motor Behaviors, Interaction and Playfulness During Mother-Child and Father-Child Play with Children with Motor Delay. Physical \& Occupational Therapy in Pediatrics, 26 (1/2), 129-151.

Csikszentmihalyi, M. \& Bennett, S. (1971) An Exploratory Model of Play. American Anthropologist, 73:45-58.

Dixon-woods M., Booth, A., \& Sutton, A.J. (2007) Synthesizing qualitative research: a review of published reports. Qualitative Research, 7(3), 375-422.

Egilson, S. T. \& Traustadottir, R. (2009) Participation of students with physical disabilities in the school environment. The American journal of occupational therapy, 63(3), 264-272. 
Garside, R. (2013) Should we appraise the quality of qualitative research reports for systematic reviews, and if so, how? Innovation: The European Journal of Social Science Research, 1-13.

Gcaza, S. \& Lorenzo, T. (2008) Discovering the barriers that stop children with disabilities from being children: The impact of lack of access to mobility devices a human rights perspective. South African Journal of Occupational Therapy, 38(1), 16-21.

Gmitrova, K., Podhajecka, M., \& Gmitrov, J. (2009) Children's play preferences: implications for the preschool education. Early Child Development and Care, 179(3), 349351.

Goodley, D., \& Runswick-Cole, K. (2010) Emancipating play: dis/ abled children, development and deconstruction. Disability \& Society, 25(4), 499-512.

Graham, N., Truman, J., \& Holgate, H. (2014) An exploratory study: expanding the concept of play for children with severe cerebral palsy. British Journal of Occupational Therapy, 77(7), 358-365.

Graham, N.E., Truman, J., \& Holgate., H. (2015). Parents' understanding of play for children with Cerebral Palsy. The American Journal of Occupational Therapy, 69(3), 1-9.

Hakstad, R.B., Obstfelder, A., \& Oberg, G.K. (2015) Parents' Perceptions of Primary Health Care Physiotherapy With Preterm Infants: Normalization, Clarity, and Trust. Qualitative Health Research, 1-10.

Hewitt-Taylor, J. (2009) Children with complex, continuing health needs and access to facilities. Nursing Standard, 23(31), 35-41.

Howard, J. (2002) Eliciting young children's perceptions of play, work and learning using the activity apperception story procedure. Early Child Development and Care, 127(5), 489-502. Howard, J., Jenvey, V., \& Hill, C. (2006) Children's categorisation of play and learning based on social context. Early Child Development and Care, 176(3-4), 379-393.

Imms, C., King, G., Majnemer, A., Avery, L., Chiarello, L., Palisano, R., Orlin, M., Law, M. (2017) Leisure participation-preference congruence of children with cerebral palsy in Canada and Australia: a Children's Assessment of Participation and Enjoyment International Network descriptive study. Developmental Medicine and Child Neurology, 59, 380-87. 
King G., Petrenchik T., Law M., \& Hurley P. (2009) The enjoyment of formal and informal recreation and leisure activities: a comparison of school aged children with and without physical disabilities. International Journal of Disability Development and Education, 56 (2), 109-130.

Kolehmainen, N., Francis, J.J., Ramsay, C.R., Owen, C., McKee, L., Ketelaar, M. \& Rosenbaum, P. (2011) Participation in physical play and leisure: developing a theory- and evidence-based intervention for children with motor impairments. BMC Pediatrics, 11(100), $1-8$.

Kable, A.K., Pich, J., \& Maslin-Prothero S.A. (2012) A structured approach to reporting a search strategy for authors. Nurse education today, 32, 878-886.

King, N.R. (1979) Play: The kindergartners' perspective. The Elementary School Journal, 80, 80-87.

King, P., \& Howard, J. (2014) Children's Perceptions of Choice in Relation to their Play at Home, in the School Playground and at The Out-of-School Club. Children and Society, 28, $116-127$.

Lester, S., \& Russell, W. (2008) Play for a Change. Play, policy and practice: A review of contemporary perspectives summary report. National Children's Bureau, London, UK.

McInnes, K., Howard, J., Miles, G.E., \& Croley, K. (2009) Behavioural differences exhibited by children when practising a task under formal and playful conditions. Educational \& Child Psychology, 26(2), 31-39.

McLean, D.D., \& Hurd, A.R. (2011) Kraus' recreation and leisure in modern society ( $9^{\text {th }}$ edition). Jones \& Bartlett learning, London, UK.

Miller, S. \& Reid, D. (2003) Doing play: competency, control, and expression. Cyberpsychology \& Behavior, 6(6), 623-32.

Moher, D., Liberati, A., Tetzlaff, J., Altman, D.G., \& The PRISMA Group (2009) Preferred Reporting Items for Systematic Reviews and Meta-Analyses: The PRISMA Statement. British Medical Journal, 21, 339.

Mundhenke, L., Hermansson, L. \& Nätterlund, B.S. (2010) Experiences of Swedish children with disabilities: activities and social support in daily life. Scandinavian Journal of Occupational Therapy, 17(2), 130-139. 
Neumann, E.A. (1971) The Elements of Play. Ardent Media, New York: USA.

Nicholson, E., Murphy, R., Larkin, P., Normand, C., Guerin, S., (2016) Protocol for a thematic synthesis to identify key themes and messages from a palliative care research network. BMC notes, 9(478), 1-5.

Parten, M.B. (1932) Social participation among preschool children. Journal of Abnormal and Social Psychology, 27, 243-269.

Polatajko, H.J., Davis, J., Stewart, D., Cantin, N., Amoroso, B., Purdie, L., \& Zimmerman, D. (2007) Specifying the domain of concern: occupation as core. In: Enabling occupation II: Advancing an occupational therapy vision for health, well-being \& justice through occupation. (eds E.A. Townsend, \& H.J. Polatajko), pp. 13-36. CAOT Publications ACE, Ottawa, ON.

Pollock, N., Steward, D., Law, M., Sahagian-Whalen, S., Harvey, S., \& Toal, C. (1997) The meaning of play for young people with physical disabilities. Canadian Journal of Occupational Therapy, 64, 25-31.

Powrie, B., Kolehmainen, N., Turpin, M., Ziviani, J., \& Copley, J. (2015) The meaning of leisure for children and young people with physical disabilities: a systematic evidence synthesis. Developmental Medicine and Child Neurology, 57(11), 993-1010.

Reilly, M. (1974) Play as exploratory learning: studies of curiosity behaviour. Sage, London, UK.

Ripat, J., Becker, P. (2012) Playground Usability: What do playground users say? Occupational Therapy International, 19, 44-153.

Robinson, S. (2011) What play therapists do within the therapeutic relationship of humanistic/ non-directive play therapy. Pastoral Care in Education, 29(3), 207-220. Rogers, S., \& Evans, J. (2006) Playing the game? Exploring role play from children's perspectives. European Early Childhood Education Research Journal, 14(1), 43-55.

Schiariti, V., Sauve, K., Klassen, A. F., O’Donnell, M., Cieza, A., \& Masse, L. (2014) “He does not see himself as being different": the perspectives of children and caregivers on relevant areas of functioning in cerebral palsy. Developmental medicine and child neurology, 56(9) 853-61. 
Schiller F. (1954) [1875]. Essays, Aesthetics and philosophical. R. Snell, translator. George Bell and Sons, London, UK.

Sheridan, M.D., Howard, J., \& Alderson, D. (2011) Play in early childhood from birth to six years (3rd edition). Routledge, London, UK.

Shikako-Thomas, K., Shevell, M., Lach, L., Law, M., Schmitz, N., Poulin, C., Majnemer, A., \& QUALA group. (2013) Picture me playing- A portrait of participation and enjoyment of leisure activities in adolescents with cerebral palsy. Research in Developmental Disabilities, 34(3), 1001-1010.

Skär, L. (2002) Disabled children's perceptions of technical aids, assistance and peers in play situations. Scandinavian Journal of Caring Science, 16, 27-34.

Sonday, A. \& Gretschel, P. (2016) Empowered to Play: A Case Study Describing the Impact of Powered Mobility on the Exploratory Play of Disabled Children. Occupational therapy international, 23(1) 11-18.

Spencer-Cavaliere, N., \& Watkinson, E.J. (2010) Inclusion understood from the perspectives of children with disability. Adapted Physical Activity Quarterly, 27, 275-293.

Tamm, M., Skär, L. (2000) How I play: roles and relations in the play situations of children with restricted mobility. Scandinavian Journal of Occupational Therapy, 7, 174-182.

Thomas, J., \& Harden, A. (2008) Methods for the thematic synthesis of qualitative research in systematic reviews. BMC Medical Research Methodology, 8(45), 1-10.

Turnbull, J. \& Jenvey, V.B. (2006) Criteria used by adults and children to categorize subtypes of play, Early Child Development and Care, 176(5), 539-551.

UNICEF, (1989). Fact sheet: A summary of the rights under the Convention on the Rights of the Child. Retrieved from http://www.unicef.org/crc/files/Rights_overview.pdf</eref $>$

Whitebread, D., Basilio, M., Kuvalja, M., \& Verm, M. (2012) The importance of play. Toy Industries of Europe, Brussels.

Whittingham, K., Fahey, M., Rawicki, B., \& Boyd, R. (2010) The relationship between motor abilities and early social development in a preschool cohort of children with cerebral palsy. Research in Developmental Disabilities, 31, 1346-1351. 
Wing, L. (1995) Play is not the work of the child: young children's perceptions of work and play. Early Childhood Research Quarterly, 10(4), 223-247.

World Health Organisation, (2007) International classification of functioning, disability and health: children and youth version. Retrieved from http://apps.who.int/iris/bitstream/10665/43737/1/9789241547321 _eng.pdf Young, B., Rice, H., Dixon-Woods, M., Colver, A.F., \& Parkinson, K.N. (2007) A qualitative study of the health-related quality of life of disabled children. Developmental Medicine \& Child Neurology, 49, 660-665. 